\title{
Schizophrenia Plasma Autoantibodies Promote 'Biased Agonism' at the 5-Hydroxytryptamine 2A Receptor: Neurotoxicity is Positively Modulated by Metabotropic Glutamate 2/3 Receptor Agonism
}

\author{
Mark B. Zimering ${ }^{1,2, *}$, Shree G. Nadkarni ${ }^{1}$ \\ ${ }^{1}$ Veterans Affairs New Jersey Healthcare System, East Orange, NJ, USA \\ ${ }^{2}$ Rutgers-Robert Wood Johnson Medical School, New Brunswick, NJ, USA \\ ${ }^{*}$ Corresponding author: Mark Zimering MD PhD, Chief of Endocrinology, Medical Service (111), 151 Knollcroft Rd, Lyons, NJ 07939, USA; Tel: +19086470180; E-mail: mark. \\ zimering@va.gov
}

Received: June 13, 2019; Accepted: June 27, 2019; Published: August 14, 2019;

\begin{abstract}
Aims: To test whether neurite-inhibitory plasma autoantibodies in chronic schizophrenia activate Gq/11- and Gi- coupled signaling pathways downstream of 5-hydroxytryptamine $2 \mathrm{~A}$ receptor activation; and for modulation of serotonergic signaling by the metabotropic $2 / 3$ receptor agonist LY379268

Methods: Plasma from five older adults with chronic schizophrenia and eight age-matched patients having another neuropsychiatric, immune or metabolic disorder was subjected to Protein-A affinity chromatography to obtain IgG autoantibodies. Mean neurite retraction (5 minutes) or cell survival (24 hours) was determined in mouse N2A neuroblastoma cells incubated with autoantibodies in the presence or absence of specific antagonists of the Gq/11/PLC/IP3R signaling pathway, Gi-coupled, beta-arrestin2-directed pathways, or LY379268.

Results: Chronic schizophrenia plasma autoantibodies- mediated dose- and time-dependent acute N2A neurite retraction was completely prevented by M100907, a selective 5-hydroxytryptamine 2A receptor antagonist. LY379268 promoted autoantibody-induced neurite retraction causing a shift-to-theleft in the dose-response curve. Antagonists of the RhoA/Rho kinase and Gq/11/PLC/IP3R signaling pathways blocked autoantibody-mediated neurite retraction. Chronic schizophrenia plasma autoantibodies mediated increased N2A cell survival which was blocked by LY379268, pertussis toxin, and antagonists of PI3-kinase- mediated survival signaling.

Conclusion: Schizophrenia plasma autoantibodies activate the 5-hydroxytryptamine 2A receptor positively coupled to Gq/11/PLC/IP3R pathway and RhoA/Rho kinase signaling activation in promoting acute N2A cell neurite retraction. Autoantibodies in a subset of patients experiencing hallucinations promoted increased N2A cell survival mediated (in part) via a pertussis-toxin sensitive, Gi-coupled, PI3-kinase-dependent mechanism. Positive modulation of 5-HT2AR-mediated neurite retraction by LY379268 suggests the autoantibodies may target (in part) the 5-HT2AR/mGlu2R heteromer.
\end{abstract}

\section{Introduction}

The serotonin 2A receptor (5-HT2AR) is highly expressed in cortical brain regions underlying normal perception [1]. The hallucinogenic drug lysergic acid diethylamine (LSD) causes longlasting 5-HT2AR activation which is positively coupled to Gq/11- and $\beta$-arrestin-2- dependent signaling pathway activation [2]. Head twitch in mice infused with the hallucinogenic (reversible 5HT2AR agonist) 1-[2,5-dimethoxy-4-iodophenyl]- 2-aminopropane (DOI) required an additional contribution from metabotropic glutamate (mGlu)2Rmediated, Gi-coupled signaling since head twitch was not observed in DOI-treated mice harboring an mGlu2R knock-out mutation [3]. Heteromeric 5-HT2AR/mGlu2R complexes occur in the mammalian prefrontal cortex [4] and are thought to integrate serotonergic and glutamatergic signals via allosteric receptor-receptor interactions alters the balance between Gq11- and Gi-coupled signaling pathway activation [4].

Paranoid schizophrenia is a common disabling disease affecting $\sim 1 \%$ of adults [5]. Evidence from epidemiologic studies [6] and a recent genome-wide association study [7] suggests a role for dysregulated acquired immunity in the pathophysiology of schizophrenia. A possible role for brain reactive autoantibodies was suggested by prior studies [6] including our report that plasma IgG autoantibodies in a subset of chronic schizophrenia potently suppressed neurite outgrowth and mediated strong depolarization in N2A mouse neuroblastoma cells [8]. Since major depression and Parkinson's disease autoantibodies mediated long-lasting 5-HT2A receptor activation positively coupled to $\mathrm{Gq} / 11$ signaling $[9,10]$, here we tested whether chronic paranoid schizophrenia plasma autoantibodies activate 5-HT2A receptor, Gq/11-mediated signaling leading to neurite outgrowth inhibition 
Mark B. Zimering (2019) Schizophrenia Plasma Autoantibodies Promote 'Biased Agonism' at the 5-Hydroxytryptamine 2A Receptor: Neurotoxicity is Positively Modulated by Metabotropic Glutamate 2/3 Receptor Agonism

in N2A mouse neuroblastoma cells. A role for signaling cross-talk involving 5 -HT2AR/mGlu2R heteromers was tested by comparing $\mathrm{N} 2 \mathrm{~A}$ acute neurite retraction induced by schizophrenia plasma autoantibodies in the presence or absence of the mGlu2/3R agonist LY379268. Since LY379268 was previously reported to suppress hallucinogen-induced Gi-coupled signaling at the 5HT2AR [4], we investigated biased 5-HT2AR-dependent, Gi-coupled signaling evoked by autoantibodies from subgroups of psychosis-prone $v s$. patients not experiencing recurrent visual or auditory hallucinations.

\section{Participants and Methods}

Participants- Outpatient men ranging in age from 47-78 years old provided informed consent for participation in the Institutional Review Board-approved study and were consecutively enrolled from the diabetes and endocrinology clinics at the Veterans Affairs New Jersey Health Care System (East Orange and Lyons, New Jersey).

\section{Psychosis-prone patients}

Patient 1: A 61- year- old man with a history of chronic paranoid schizophrenia and multiple recurrent hospitalizations for auditory hallucinations and one previous suicide attempt. The patient has type 2 diabetes mellitus of approximately eight years duration without microvascular complications.

Patient 2: A 55- year- old man with chronic paranoid schizophrenia, three previous suicides attempts, and type 2 diabetes (of five years known duration) without microvascular complications.

Patient 3: A 61-year-old man having major depressive disorder with mood-incongruent psychotic features and type 2 diabetes of fourteen years duration.

Patient 4: A 47-year-old man with chronic schizophrenia, and no history of type 2 diabetes. He had paranoid delusions without any suicide attempt.

Blood samples: Blood was drawn in the morning after an overnight fast. Plasma or serum was stored at $-20 \mathrm{C}$.

Protein A affinity chromatography- Protein-A affinity was performed as previously described [10].

N2A mouse neuroblastoma cells: were cultured in Dulbecco's modified Eagles medium (DMEM) containing 10\% fetal calf serum. Cells were fed with fresh medium every 1-2 days, except for survival assays in which fresh medium was not added for up to 5 days prior to the addition of test autoantibody fractions.

Acute neurite retraction assay: \% of basal neurite length in N2A cells expressing one or more proximally-located dendrite-like process was determined after interval exposure to test substances as previously reported [10].

N2A cell survival: MTT assay was performed 24 hours after incubation with test substances as previously reported [10].
Chemicals: all chemicals were obtained from Sigma, Co., Inc. (St Louis, MO), except YM-254890 (Focus Biomolecules) and LY 379268 (Tocris Bioscience).

Protein assay: protein concentration was determined using a modified bichichonic acid assay (Bio Rad. Inc.).

Statistics- Paired and unpaired T-tests were used to assess for statistically significant differences between groups or between treatments.

\section{Results}

\section{Baseline characteristics in the study patients}

The clinical characteristics in the study patients are shown in (Table 1). Patients having chronic schizophrenia did not differ significantly in their mean age, body mass index or glycosylated hemoglobin level from patients having Parkinson's disease $(n=5)$, dementia $(n=1)$, or diabetic nephropathy $(\mathrm{n}=1)$.

Table 1. Clinical characteristics in the study participants

\begin{tabular}{|l|c|c|c|}
\hline Diagnosis & Age (years) & $\mathbf{H b A}_{\mathbf{1}} \mathbf{c}(\mathbf{\%})$ & $\mathbf{B M I}\left(\mathbf{k g} / \mathbf{m}^{\mathbf{2}}\right)$ \\
\hline Schizophrenia (n=5) & $61.4+9.7$ & $7.0+1.1$ & $31.7+8.1$ \\
\hline PD or Other (n=7) & $70.6+5.5$ & $7.2+1.4$ & $33.1+6.2$ \\
\hline Diabetes without MVD (n=2) & $77.5+6.1$ & $7.2+0.2$ & $33.5+5.3$ \\
\hline
\end{tabular}

*Parkinsons disease (PD) $(n=4)$, major depressive disorder $(n=1)$, diabetic nephropathy $(n=1)$, dementia ( $n=1)$. MVD- microvascular disease.

\section{Acute N2A neurite retraction from schizophrenia plasma} IgG fractions

Schizophrenia plasma autoantibodies (at IgG concentrations $>10 \mathrm{nM}$ ) caused dose-dependent N2A neurite retraction which significantly exceeded neurite retraction in an identical concentration of IgG from two older adult type 2 diabetes patients without microvascular, neuropsychiatric or neurodegenerative complications (Figure 1A). Neurite retraction in response to potent schizophrenia plasma autoantibodies, e.g. Pt 1, was linear, irreversible and more than $50 \%$ neurite withdrawal occurred after 5 minutes' exposure time (Figure 1B).

A

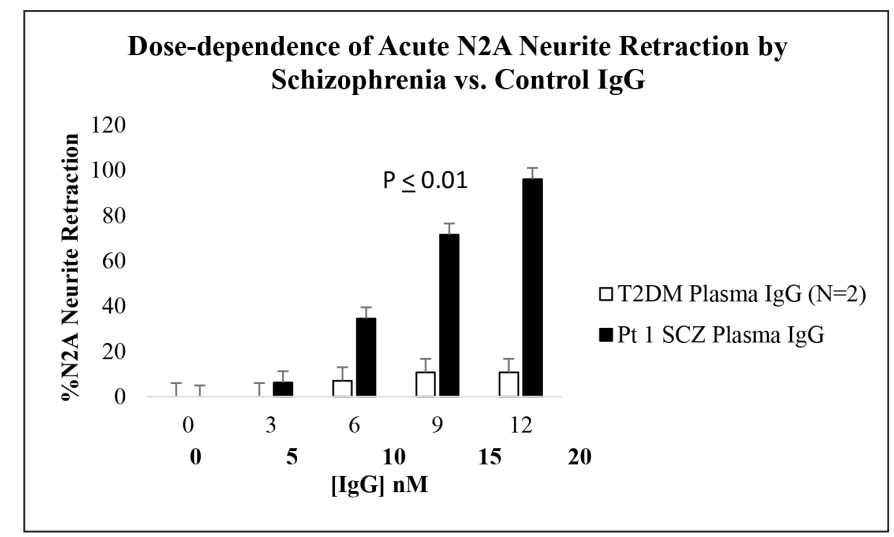


Mark B. Zimering (2019) Schizophrenia Plasma Autoantibodies Promote 'Biased Agonism' at the 5-Hydroxytryptamine 2A Receptor: Neurotoxicity is Positively Modulated by Metabotropic Glutamate 2/3 Receptor Agonism

B

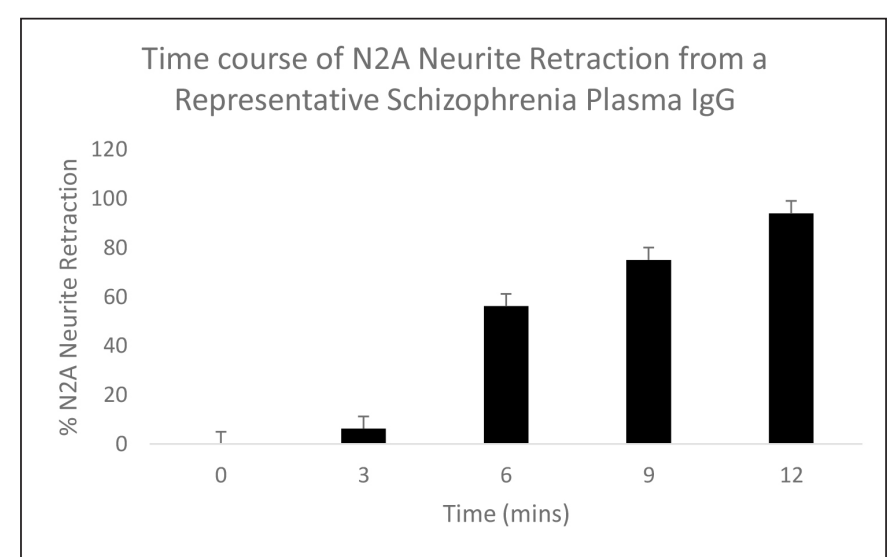

Figure 1. A) Dose-dependent or B) time-dependent acute neurite retraction induced by diabetic schizophrenia plasma autoantibodies (solid bars; Pt 1) or (A) by the autoantibodies from two older diabetic patients not suffering with diabetic microvascular complications or any neuropsychiatric or neurodegenerative complication (open bars). Results represent mean + SE determined as described in Materials and Methods. B) Similar results were obtained in the plasma autoantibodies from all five of five schizophrenia patients tested.

Schizophrenia (SCZ) plasma autoantibody-induced neurite retraction was completely prevented by co-incubation with a twohundred nanomolar concentration of the selective 5HT2A receptor antagonist, M100907 (Table 2). Slightly higher concentrations (500 nM) of the 5-HT2A receptor antagonists spiperone and ketanserin afforded significant protection ( $~ 50-80 \%)$ against SCZ plasma autoantibodyinduced neurite retraction (Table 2). A higher concentration (1-10 $\mu \mathrm{M})$ of selective antagonists of the endothelin $\mathrm{A}$, angiotensin type 1 , alpha-1-adrenergic and 5HT2B receptors (all Gq/11-coupled GPCRs) i.e. bosentan, losartan, prazosin and SB204741, did not significantly protect (0-28\%) against schizophrenia plasma IgG-induced neurite retraction (Table 2).

Table 2. Pharmacology of schizophrenia plasma autoantibody(AutoAB)-induced neurite retraction

\begin{tabular}{|l|c|c|c|}
\hline \multicolumn{2}{|c|}{ Antagonist \% } & \multicolumn{2}{c|}{ AutoAB-induced } \\
\hline + AutoAB (20 nM) & [Concentration] & Receptor & neurite retraction \\
\hline M100907 & $200 \mathrm{nM}$ & $5 \mathrm{HT} 2 \mathrm{AR}$ & $0+0 \%$ \\
\hline Spiperone & $500 \mathrm{nM}$ & 5HT2AR & $17+6 \%$ \\
\hline Ketanserin & $500 \mathrm{nM}$ & 5HT2AR & $43+11 \%$ \\
\hline SB204741 & $1 \mu \mathrm{M}$ & $5 \mathrm{HT} 2 \mathrm{BR}$ & $100+0 \%$ \\
\hline Bosentan & $10 \mu \mathrm{M}$ & ETAR & $94+7 \%$ \\
\hline Losartan & $10 \mu \mathrm{M}$ & AT1R & $72+8 \%$ \\
\hline Prazosin & $1 \mu \mathrm{M}$ & A1AR & $72+10 \%$ \\
\hline
\end{tabular}

A twenty nanomolar concentration of the Pt 1 schizophrenia protein-A eluate fraction of plasma was incubated with $\mathrm{N} 2 \mathrm{~A}$ cells in the presence or absence of the indicated concentration of each Gq/11, GPCR antagonist. Results are the mean +/- SD of two experiments

\section{Mechanism of schizophrenia plasma IgG-induced neurite retraction}

Major depressive disorder and Parkinson's disease plasma IgG autoantibodies were previously reported to cause acute N2A neurite retraction through a mechanism involving activation of the RhoA/ Rho kinase and PLC/IP3R/Ca2+ signaling pathways [9,10]. In the present study, neurite retraction induced by SCZ plasma IgG autoantibodies was completely prevented by co-incubating N2A cells with a ten micromolar concentration of the selective Rho kinase inhibitor Y27632 or a one micromolar concentration of the selective Gq11 inhibitor Y254890 (Table 3). In addition, a one micromolar concentration of the phospholipase C inhibitor U73122, and a 50 micromolar concentration of the IP3R antagonist 2-APB each significantly protected (72-83\%) against SCZ IgG-induced neurite retraction (Table 3). Taken together, these data suggest that SCZ IgG induced neurite retraction likely involves activation of both RhoA/ Rho kinase and Gq/11/PLC/IP3R/Ca2+ signaling pathways.

Table 3. Mechanism of acute N2A neurite retraction induced by schizophrenia plasma AutoAB

\begin{tabular}{|l|c|c|}
\hline \multicolumn{1}{|c|}{ Treatment } & Conc & $\begin{array}{c}\text { \% of AutoAB- } \\
\text { induced neurite } \\
\text { retraction }\end{array}$ \\
\hline $\mathrm{SCZ} \mathrm{IgG} \mathrm{(N=2)} \mathrm{alone}$ & $40 \mathrm{nM}$ & $100+0 \%$ \\
\hline AutoAB + Y27632 (ROCK inhibitor) & $10 \mathrm{uM}$ & $0+0 \%$ \\
\hline AutoAB + 2-APB (IP3R antagonist) & $50 \mathrm{uM}$ & $17+1.9 \%$ \\
\hline AutoAB + U73122 (PLC inhibitor) & $1 \mathrm{uM}$ & $28+15 \%$ \\
\hline AutoAB + YM-254890 (Gq11 inhibitor) & $1 \mathrm{uM}$ & $0+0 \%$ \\
\hline
\end{tabular}

A forty nanomolar concentration of the Pt 1 or Pt 2 schizophrenia plasma autoantibodies (AutoAB) was incubated in the presence or absence of the indicated concentration of RhoA/Rho kinase (ROCK) inhibitor, or individual antagonists of the Gq11/PLC/IP3R signaling pathway. Results are (mean $+/-\mathrm{SD}$ ) acute N2A neurite retraction occurring in response to Pt 1 or Pt 2 IgG autoantibodies.

\section{Modulation of SCZ IgG-induced neurite retraction by LY379268, a potent $\mathrm{mGlu2/3R}$ agonist}

Cross-signaling between Glu2/3R and 5HT2AR was inferred from differences in IgG-induced N2A acute neurite retraction occurring in the presence or absence of the mGlu2/3R agonist LY379268, at 5-10 $\mu \mathrm{M}$ concentrations (of LY379268) which alone had no effect on neurite retraction. The mGlu2/3R agonist LY379268 was previously reported to cause positive allosteric modulation of the 5HT2AR protomer affinity at $5 \mathrm{HT} 2 \mathrm{AR} / \mathrm{mGlu} 2 \mathrm{R}$ heteromers [4]. A one microgram per milliliter concentration $(\sim 7 \mathrm{nM})$ of the potent Pt 1 , SCZ plasma IgG autoantibodies caused 50\% inhibition of N2A neurite outgrowth (Figure 2A). Pre-incubation (for 5 minutes) followed by co-incubation of N2A cells with a 10 micromolar concentration of LY379268 caused a 'shift to the left' in the dose-response curve of the Pt 1 plasma IgG-induced neurite retraction: $50 \%$ inhibition of N2A neurite outgrowth occurred at substantially lower, i.e. $~ 0.5$ microgram per milliter concentration $(3.5 \mathrm{nM})$ of Pt 1 IgG autoantibodies (Figure 2A). The "potentiating effect" of $10 \mu \mathrm{M}$ LY379268 on neurite retraction was more pronounced at low concentrations of SCZ plasma IgG ranging from (3.5-14 nM) (Figure 2A). Presumably, at these lower concentrations a high proportion of unoccupied 5HT2A receptors are available to undergo positive allosteric modulation via mGlu2R protomer binding to LY379268. The dose-response curve for DOI-induced neurite retraction underwent a 'shift- to-the-left' in 
Mark B. Zimering (2019) Schizophrenia Plasma Autoantibodies Promote 'Biased Agonism' at the 5-Hydroxytryptamine 2A Receptor: Neurotoxicity is Positively Modulated by Metabotropic Glutamate 2/3 Receptor Agonism

the presence of $(10 \mu \mathrm{M}) \mathrm{LY} 379268$ : the concentration of DOI needed to evoke $25-30 \%$ neurite inhibition decreased from $10 \mu \mathrm{M}$ (in the absence of LY379268) to $5 \mathrm{uM}$ in the presence of LY379268 (Figure 2B). A saturating concentration of the reversible 5-HT2AR agonist DOI $(20 \mu \mathrm{M})$ caused $40 \%$ peak neurite retraction compared to $50 \%$ neurite retraction induced by an $\sim 2000$-fold lower concentration ( 7 $\mathrm{nM}$ ) of potent SCZ plasma IgG autoantibodies (Figure 3).

A

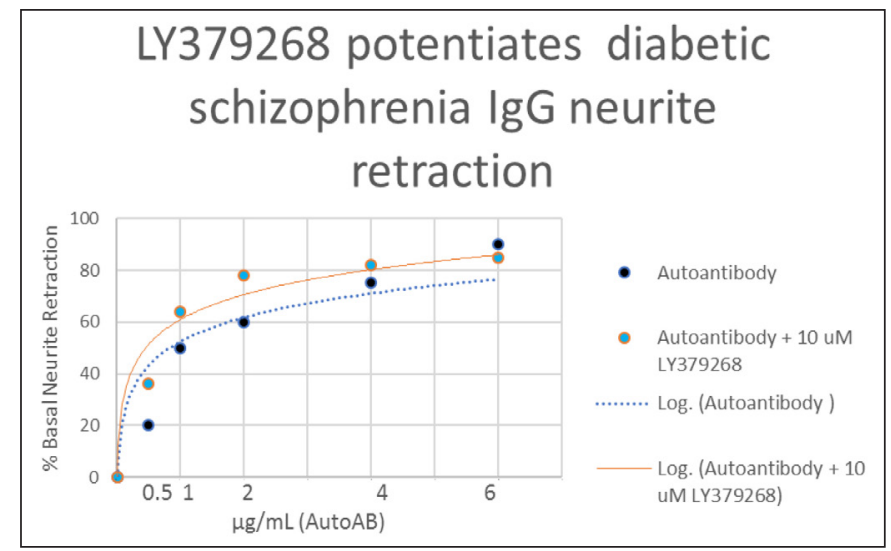

B

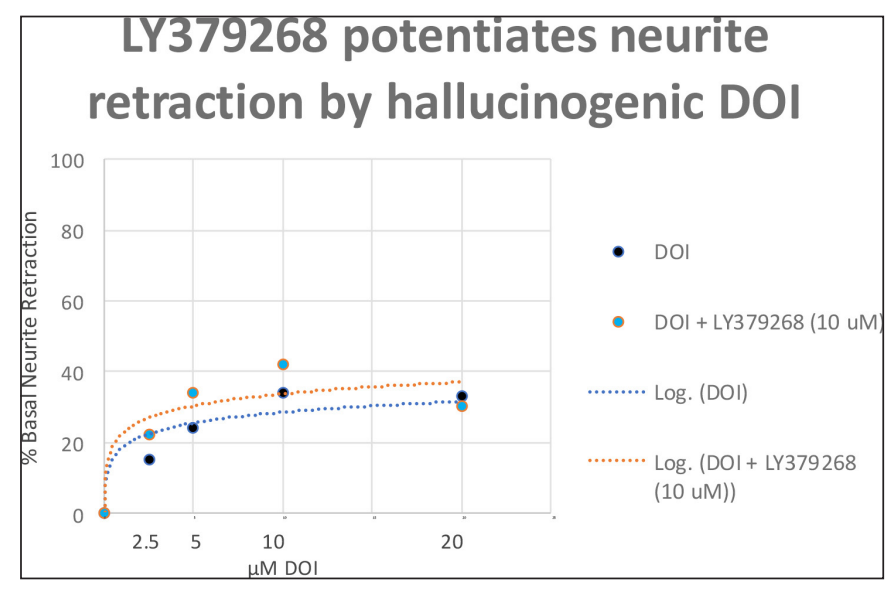

Figure 2. A) Diabetic schizophrenia Pt plasma autoantibodies or B) the hallucinogen DOI was incubated at the indicated concentrations in the presence (orange symbol) or absence (blue symbol) a 10 micromolar concentration of LY379268 in N2A cells. Each point represents mean acute neurite retraction which varied by $<10 \%$. A) Similar result was obtained in the diabetic schizophrenia Pt 2 plasma autoantibodies.

LY379286-potentiated SCZ plasma IgG autoantibody-induced neurite retraction was significantly prevented by co-incubation with the highly selective 5HT2AR antagonist M100907 (500 nM) suggesting mGlu2/3R agonism enhanced neurite retraction via 5HT2AR-dependent signaling. One possibility is that an mGlu2/3R agonist increased 5HT2AR receptor affinity for SCZ plasma IgG autoantibodies via a heteromeric receptor-receptor interaction as was previously reported for mGlu2/3 agonist action at the 5HT2AR/ mGlu2R complex [4].

Potentiation of 5HT2AR- mediated neurite retraction (by a $10 \mu \mathrm{M}$ concentration of LY379268) was observed in the IgG autoantibodies from twelve patients tested including: chronic paranoid schizophrenia $(n=5)$, Parkinson's disease $(n=5)$, dementia $(n=1)$ and diabetic nephropathy $(\mathrm{n}=1)$. The mean level of neurite retraction (induced by an IgG concentration which alone caused $~ 50 \%$ retraction) was significantly increased in the presence of $10 \mu \mathrm{M} \mathrm{LY} 379268(74+10 \%$ vs $52+7 \% ; \mathrm{P}<0.001 ; \mathrm{n}=12$ ) (Table 4$)$.

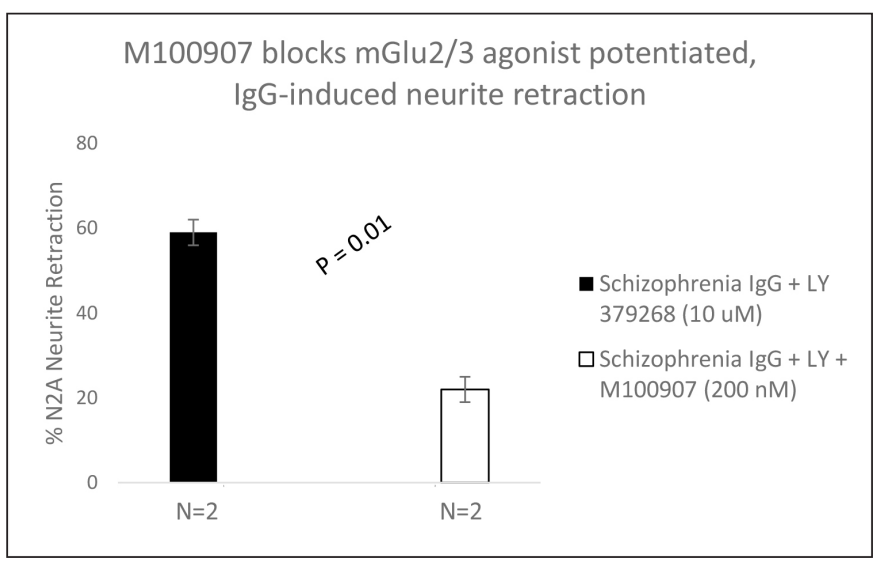

Figure 3. Schizophrenia plasma autoantibodies $(\mathrm{Pt} 1,2)$ was incubated with a micromolar concentration of LY379268 alone (solid bars) or with (open bars) a two-hundred nanomolar concentration of the selective 5-HT2AR antagonist M100907 in N2A cells. Results are mean $+\mathrm{SE}$ as described in Materials and Methods.

Table 4. Mean N2A neurite retraction induced by neurovascular pathologies' AutoAB in the presence or absence of $(7.5-10 \mu \mathrm{M})$ LY379268, a selective mGlu2/3R agonist

\begin{tabular}{|l|l|l|l|l|}
\hline Pathologies (N=12) & $\begin{array}{l}\text { Mean } \\
\text { [IgG]. }\end{array}$ & Pt IgG. & $\begin{array}{l}\text { Pt IgG + } \\
\text { LY379268 }\end{array}$ & P-value \\
\hline $\begin{array}{l}\text { Schizophrenia (5), } \\
\text { PD(4), }\end{array}$ & $17+6 \mathrm{nM}$ & $52+7 \% \wedge$ & $74+10 \%{ }^{\wedge}$ & $<0.001$ \\
\hline Other (3) & & & & \\
\hline
\end{tabular}

${ }^{\wedge}$ Mean acute N2A neurite retraction (after five minutes' incubation) in the presence of the indicated mean concentration of plasma autoantibodies (protein-A eluate fraction) with or without a $7.5-10 \mu \mathrm{M}$ concentration of the mGlu2/3R agonist LY379268.

Other pathologies: $n=1$ dementia, $n=1$ diabetic nephropathy, $n=1$ major depressive disorder

\section{Balanced Gq/11- and Gi/o-coupled signaling in response to SCZ plasma IgG autoantibodies}

Second generation anti-psychotic medications, e.g. clozaril, risperodone, exhibit high affinity binding to 5-HT2AR and bias 5-HT2AR signaling in favor of Gi- coupled pathways [11]. They also bind less avidly to the dopamine 2 receptor, D2R [11]. The reversible 5-HT2AR hallucinogenic agonist DOI biases signaling in favor of Gq/11 [12]. Yet the irreversible 5-HT2AR agonist LSD, and serotonin and its psychoactive metabolites promotes a mix of Gi- and Gq/11 coupled signaling $[2,12]$. Psychosis can occur in subsets of major depressive disorder and in $~ 50 \%$ of Parkinson's disease patients. We next investigated whether the ability to evoke survival promotion in N2A cells might differentiate autoantibodies in a subset of psychosisprone patients and the mechanisms underlying autoantibody-induced N2A survival promotion.

Plasma IgG autoantibodies in Patients 1, 2, 4 having chronic schizophrenia $(10 \mu \mathrm{g} / \mathrm{mL})$ caused dose-dependent increased N2A cell survival compared to an identical concentration of IgG autoantibodies 
Mark B. Zimering (2019) Schizophrenia Plasma Autoantibodies Promote 'Biased Agonism' at the 5-Hydroxytryptamine 2A Receptor: Neurotoxicity is Positively Modulated by Metabotropic Glutamate 2/3 Receptor Agonism

from four patients with either MDD ( $\mathrm{n}=3$ ) or $\mathrm{PD}(\mathrm{n}=1)$, only one of whom (PD) had experienced visual hallucinations (Figure 4A). The autoantibodies from a patient with the systemic autoimmune condition discoid lupus erythematosus caused significantly greater N2A growth stimulation $(144 \%+5 \%$ vs. $102+8 \% ; \mathrm{P}<0.01)$ compared to mean growth stimulation in an identical concentration of the autoantibodies from three chronic schizophrenia patients (Figure 4A).

A

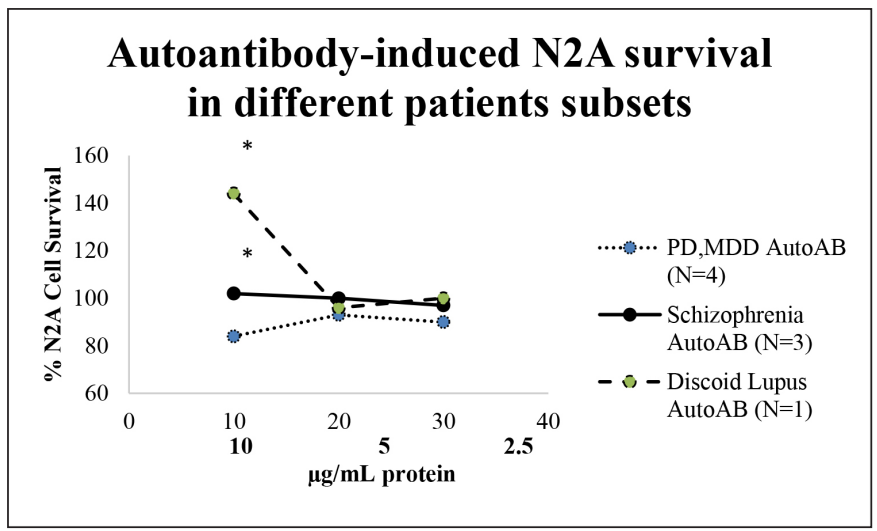

B

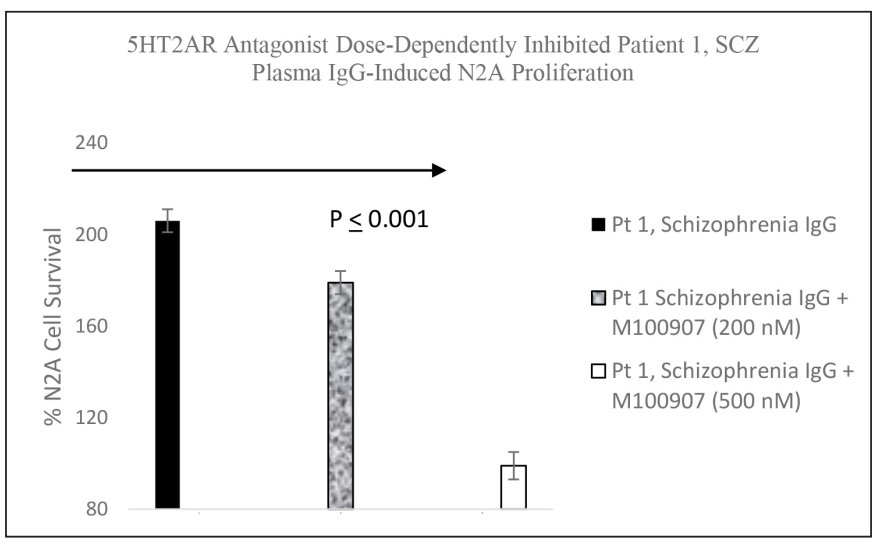

Figure 4. A) Plasma autoantibodies in three patients with schizophrenia (solid line), four patients with another disorder (dotted line), or a patient with diabetes and discoid lupus (dashed line) were incubated with N2A cells at the indicated concentrations for 24 hours. Each point represents mean N2A cell survival, i.e. quadruplicate determinations which varied by $<10 \%$

* $\mathrm{P}<0.01$ compared to solid line or dotted line B) Patient 1 diabetic schizophrenia autoantibodies $(60 \mathrm{nM})$ was incubated alone (solid bars) or with a 200 nanomolar (speckled bar) or a 500 nanomolar concentration (open bar) of the selective 5-HT2AR antagonist M100907 in N2A cells for 24 hours. Results are mean + SE.

\section{Mechanism of N2A pro-survival effect in plasma autoantibodies from psychosis-prone subset}

Serotonin $2 \mathrm{~A}$ receptor activation leads to $\beta$-arrestin-2- mediated desensitization and receptor internalization. However, $\beta$-arrestin-2 can also couple with diverse signaling pathways leading to enhanced cell proliferation and/or survival promotion. The Pt 1, chronic paranoid schizophrenia IgG autoantibodies promoted increased N2A cell proliferation which was significantly blocked by $500 \mathrm{nM}$ concentration of M100907 (Figure 4B) consistent with 5HT2AR- mediated proliferation signaling. LY379268 $(5 \mu \mathrm{M})$ alone had no effect on N2A survival, but it significantly blocked the Pt 1 and Pt 2, schizophrenia autoantibody-induced pro-survival effect on N2A cells (Figure $5 \mathrm{~A})$. Pertussis toxin $(100 \mathrm{ng} / \mathrm{mL}$ ) had no effect alone on N2A cell survival, but significantly blocked the pro-survival effect of Patient 2 SCZ IgG on N2A cells (Figure 5B). Finally, the PI3- kinase inhibitor LY294002 $(20 \mu \mathrm{M})$ significantly decreased N2A survivalpromotion induced by schizophrenia Pt 1 , and Pt 3 major depression with psychotic features autoantibodies (Figure 6A, B).

A

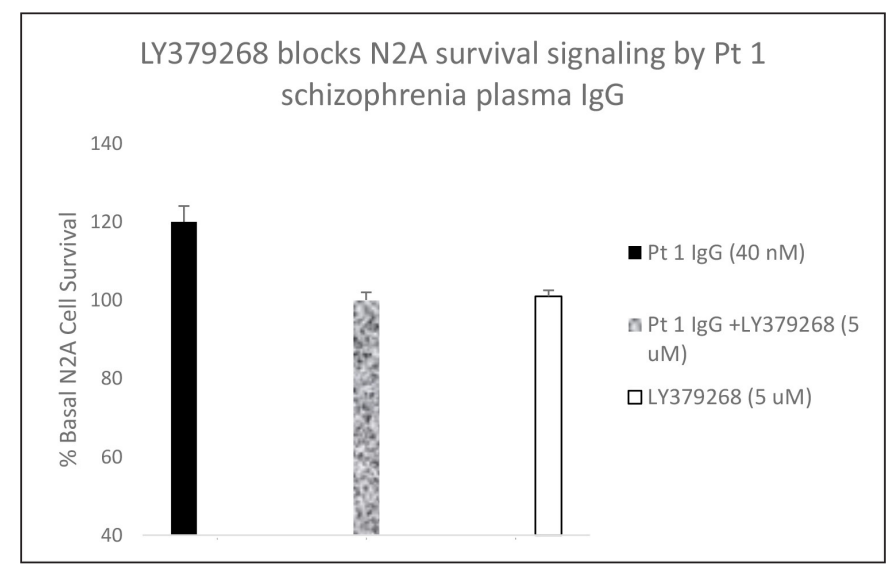

B

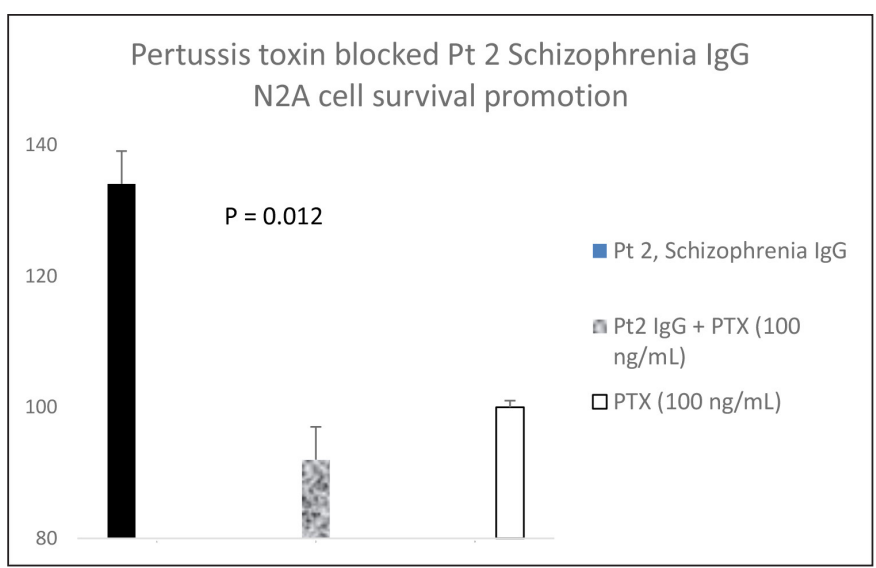

Figure 5. A) Patient 1 schizophrenia plasma autoantibodies $(40 \mathrm{nM})$ was incubated alone (solid bar) or with (speckled bar) a 5 micromolar concentration of the mGlu2R agonist LY379268 in N2A cells for 24 hours. Similar results were obtained in the plasma autoantibodies from Pt 2 chronic schizophrenia, and a Parkinson's disease patient who had been experiencing visual hallucinations. B) Patient 2 chronic schizophrenia plasma autoantibodies $(40 \mathrm{nM})$ was incubated alone (solid bar) or with (speckled bar) a $100 \mathrm{ng}$ / $\mathrm{mL}$ concentration of pertussis toxin (PTX) in N2A cells for 24 hours. A-B) Results are mean $+\mathrm{SE}$.

Possible association between psychosis and autoantibodymediated N2A survival promotion

Mean N2A survival promotion in the autoantibodies from seven patients suffering with hallucinations significantly exceeded mean N2A survival in an identical concentration of the plasma autoantibodies from four patients not suffering with hallucinations $(112+14$ vs 72 $+15 ; \mathrm{P}=0.001$ ) (Figure 7). The patient subgroups (experiencing or 
Mark B. Zimering (2019) Schizophrenia Plasma Autoantibodies Promote 'Biased Agonism' at the 5-Hydroxytryptamine 2A Receptor: Neurotoxicity is Positively Modulated by Metabotropic Glutamate 2/3 Receptor Agonism

not experiencing hallucinations) did not differ significantly in their baseline clinical characteristics (Table 5).

A

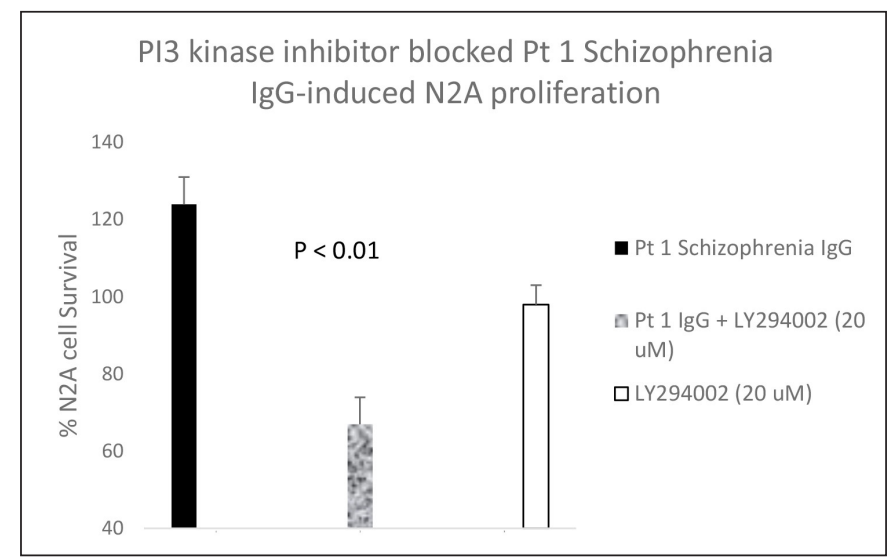

B

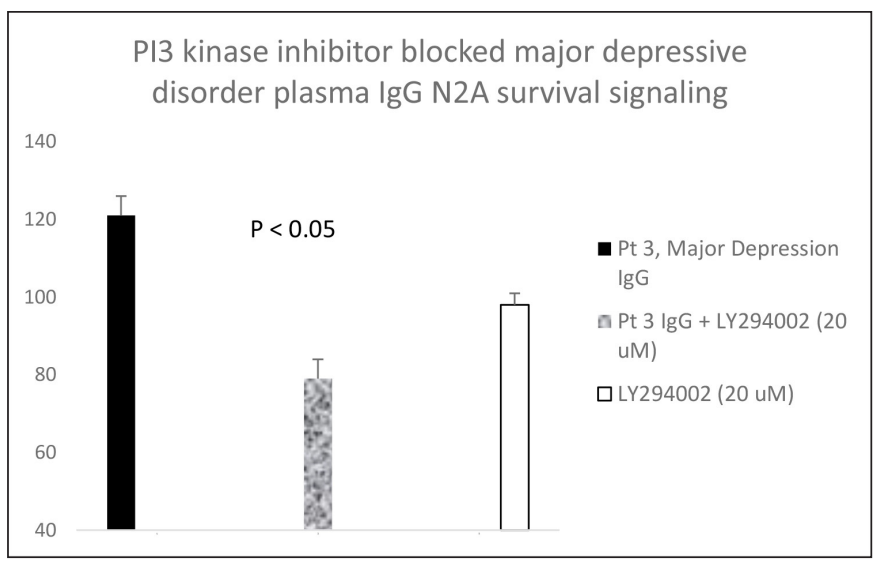

Figure 6. A) Pt 1 schizophrenia plasma autoantibodies $(40 \mathrm{nM})$ or B) Pt 3 major depression with psychotic features autoantibodies was incubated alone (solid bar) or in the presence (speckled bar) of a twenty micromolar concentration of the PI3-kinase inhibitor LY294002 in N2A cells for 24 hours. Results are mean + SE. Similar results were obtained with two additional schizophrenia patient plasma autoantibodies.

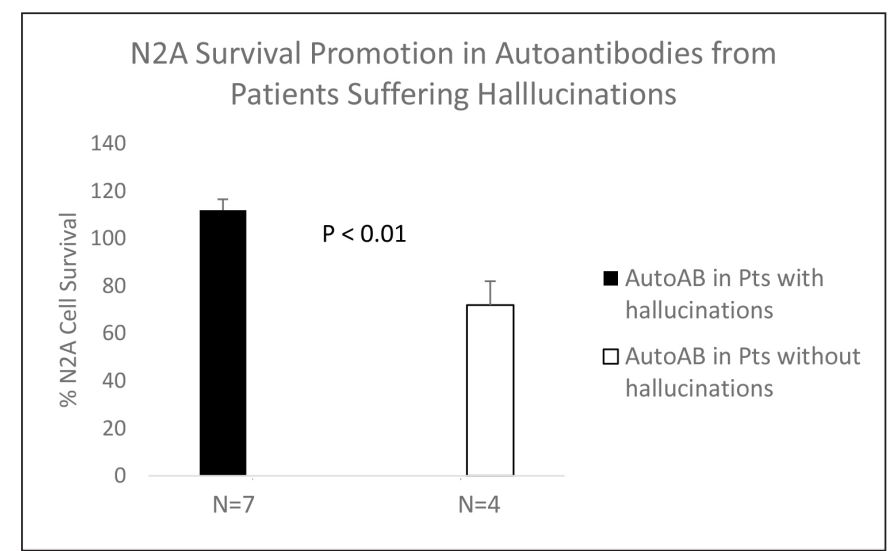

Figure 7. Mean N2A cell survival after 24 hours incubation in the presence of an identical $40 \mathrm{nM}$ concentration of the plasma autoantibodies from schizophrenia $(\mathrm{n}=5)$, major depression $(n=1)$, Parkinson's disease $(n=1)$ patients all suffering with hallucinations $(n=7$, solid bar) or from patients with major depression $(n=3)$ or diabetes without hallucinations ( $n=4$, open bar). Results are mean + SE.
Table 5. Baseline characteristics in patients suffering or not suffering hallucinations

\begin{tabular}{|l|l|l|l|}
\hline Risk factor & $\begin{array}{l}\text { Hallucinations } \\
(\mathbf{n}=\mathbf{7})^{\wedge}\end{array}$ & $\begin{array}{l}\text { No Hallucinations } \\
(\mathbf{n}=\mathbf{4})^{*}\end{array}$ & P-value \\
\hline Age (years) & $64.3+9.1$ & $71.5+15.0$ & 0.33 \\
\hline Glycosylated Hgb (\%) & $7.7+1.0$ & $7.7+0.9$ & 0.93 \\
\hline Diabetes duration (years) & $13.3+6.1(7)$ & $8.7+2.6$ & 0.30 \\
\hline
\end{tabular}

$\wedge$ Schizophrenia $(\mathrm{n}=5)$, Major depression $(\mathrm{n}=1)$, Parkinsons disease $(\mathrm{n}=1)$

* Major depression $(\mathrm{n}=3)$, type 2 diabetes without neuropsychiatric disorder $(\mathrm{n}=1)$

\section{Discussion}

Here we demonstrate (for the first time) the existence of 5-HT2AR- activating IgG autoantibodies in plasma from a subset of chronic schizophrenia patients. The autoantibodies caused potent, irreversible Gq/11-mediated neurite retraction in N2A cells by a mechanism involving activation of RhoA/ROCK and Gq11- coupled, PLC/IP3R signaling pathways. In patients suffering with severe, recurrent hallucinations and suicidal ideation, the autoantibodies also promoted N2A cell survival and/or proliferation (in part) via apparent recruitment of additional Gi-coupled, PI3-kinase-dependent survival signaling. LY379268 blocked 5HT2AR-dependent, Gi-coupled, N2A survival signaling in autoantibodies from patients suffering with hallucinations in agreement with the report of Gonzalez-Maeso et. al. [4] of similar effects of LY379268 on hallucinogen-specific induction of egr-2.

The 5-HT2A receptor mediates diverse signaling pathway activation in response to different ligands [12], a phenomenon which has been referred to as "functional selectivity" or "biased agonism." Beta-arrestin-2- directed signaling not only plays a key role in receptor internalization and desensitization, but it acts as a scaffold to organize extracellular regulated-kinase MAPK signaling cascades [13] and components of the PI3-kinase/Src/Akt cell survival pathway [14]. The latter pathway is active in cancer cells [15] including neuroblastoma [16]. Lysergic acid diethylamine (LSD) causes long-lasting 5-HT2AR activation and biased, $\beta$-arrestin-2-directed signaling [2] providing a further link between a 'mix' of Gq/11-coupled and $\beta$-arrestin-2directed signaling and psychomimetic effects associated with a subset of long-lasting 5-HT2AR agonists, i.e. schizophrenia autoantibodies.

Sensitization of autoantibody-induced neurite retraction by the mGlu2/3R agonist LY379268 is consistent with Gonzalez-Maeso et. al. [4] and suggests positive allosteric modulation of the 5HT2AR protomer affinity at functional $5 \mathrm{HT} 2 \mathrm{AR} / \mathrm{mGlu} 2 \mathrm{R}$ complexes in N2A neuroblastoma cells as a plausible mechanism. Receptor heteromers have been reported in neuroblastoma cell, e.g. A2R/D2R [17], and both 5HT2AR [9] and mGlu2R [18] are normally expressed in mouse neuroblastoma cells. Yet in our preliminary experiments, the dopamine 2 receptor (D2R) agonist quinpirole $(10 \mu \mathrm{M})$ did not sensitize N2A cells to schizophrenia plasma autoantibody- $(n=4$ different patients) or DOI-induced neurite retraction suggesting that targeting of 5-HT2AR by schizophrenia plasma autoantibodies is specific for homomers or 5-HT2AR/mGlu2R heteromers.

Targeting mGlu2R agonism as a mechanism to suppress presynaptic glutamate release (via mGlu2 autoreceptors) reduced certain 
Mark B. Zimering (2019) Schizophrenia Plasma Autoantibodies Promote 'Biased Agonism' at the 5-Hydroxytryptamine 2A Receptor: Neurotoxicity is Positively Modulated by Metabotropic Glutamate 2/3 Receptor Agonism

psychomimetic drug effects in animals, but did not lead to overall reduction in both negative and positive symptoms in schizophrenia patients [19]. Sensitization of 5-HT2AR-mediated neurite withdrawal by an mGlu2/3 agonist demonstrated here (in vitro) suggests a possible mechanism in which mGlu2R agonism may promote a 'negative symptom' in schizophrenia. For example, major depression autoantibodies from patients suffering with anhedonia, a negative symptom in schizophrenia, not only caused robust Gq/11-mediated neurite retraction in $\mathrm{N} 2 \mathrm{~A}$ neuroblastoma cells [9], but also led to decreased sucrose preference, the behavioral equivalent of anhedonia, in mice following autoantibody intracerebroventicular infusion [20]. More study is needed to determine whether Gq/11-mediated neurite retraction might a useful biomarker in drug discovery aimed at reducing combined negative and positive symptoms in schizophrenia.

Excessive glutamatergic signaling in the cortex and striatum is a feature of 5-HT2AR activation which may underly (in part) delusions and hallucinations occurring in schizophrenia [21] and in a subset of Parkinson's disease. Serotonin 2A receptor agonism promotes neuronal glutamate release [22] which in turn may enhance 5-HT2AR protomer affinity at $5 \mathrm{HT} 2 \mathrm{AR} / \mathrm{mGlu} 2 \mathrm{R}$ heteromers in the prefrontal cortex. Since constitutive activation of Gq11-coupled GPCR signaling was reported to recruit additional Gi-coupled downstream signaling in independent GPCRs [23], we cannot rule out the possibility that some 'cross-talk' between 5HT2AR and mGlu2R agonism may occur (in part) via mechanisms occurring downstream of direct receptorreceptor interaction(s).

Autoantibodies in a subset of psychosis-prone individuals might possess structural characteristics which bias 5-HT2AR signaling in favor of dual Gq/11 and Gi-coupled, or $\beta$-arrestin-2-directed pathways. One possibility is circulating immune complexes which were reported to increase in patients with schizophrenia [24]. Systemic autoimmunity, characterized by a high prevalence of immune complexes, is a risk factor for schizophrenia identified in prior studies [6]. Circulating immune complexes in chronic lymphocytic leukemia (CLL) promoted increased B cell survival through activation of antiapoptotic and pro-survival signaling pathways [25] and in a prior report, the autoantibodies in a Parkinson's disease patient with CLL strongly promoted increased N2A proliferation [10]. Taken together, autoantibody-induced cancer cell proliferation and survival might suggest immune complexes which appear to promote biased signaling in favor of dual $\mathrm{Gq} / 11$-mediated and $\beta$-arrestin-2-directed pathway activation.

A limitation of our study is that it is cross-sectional. More study is needed to determine whether autoantibodies are present in acute-onset, or drug-naive schizophrenia or in other psychotic disorders. Long-standing type 2 diabetes mellitus was associated with 5-HT2AR-activating autoantibodies in patients having diffuse microvascular injury and chronic inflammation, e.g. diabetic kidney disease $[9,10]$. Yet type 2 diabetes per se is unlikely to have accounted for autoantibodies in the present subset of schizophrenia patients who were free of significant microvascular (i.e. renal or retinal) complications. Schizophrenia is thought to arise through complex gene-environment interactions leading to abnormal neurodevelopment. Brain-reactive antibodies occurring as a result of inflammation, infection or systemic autoimmunity is one potential environmental mechanism in schizophrenia causation [6].

In summary, chronic schizophrenia plasma IgG autoantibodies appeared to activate a Gq11/phospholipase C/inositol triphosphate receptor pathway and RhoA/Rho kinase signaling to cause acute N2A neurite retraction. Autoantibody-induced neurite retraction was positively modulated by the mGlu2/3R agonist LY379268 consistent with reported mGlu2R-driven, positive modulation of 5-HT2AR protomer affinity at $5 \mathrm{HT} 2 \mathrm{AR} / \mathrm{mGlu} 2 \mathrm{R}$ heteromers [4] found in cortical brain regions underlying perception. Biased agonism at 5-HT2AR mediated by the hallucinogen LSD [2] or by certain autoantibodies from patients suffering delusions and halllucinations involves recruitment of Gi-coupled, PI3-kinase-dependent mechanisms (which for the autoantibodies) was associated with enhanced survival in N2A neuroblastoma cells.

\section{Acknowledgement}

We thank Dr. S. Varia and Dr. J. Alder (Dept of Neuroscience, Rutgers-RWJ Med School) for generously providing N2A mouse neuroblastoma cells. Supported in part by a grant from the Veterans Biomedical Research Institute (East Orange, NJ) to MBZ.

The authors report no multiplicity of interest affecting the objectivity of the study results. Presented (in part) at the 2019 Experimental Biology Meeting, Orlando, Florida Supported in part by a grant from the Veterans Biomedical Research Institute, East Orange, New Jersey to MBZ.

\section{References}

1. Xu T, Pandey SC (2000) Cellular localization of serotonin(2A) (5HT(2A)) receptors in the rat brain. Brain Res Bull 51: 499-505. [crossref]

2. Wacker D, Wang S, McCorvy JD (2017) Crystal Structure of an LSD-Bound Human Serotonin Receptor. Cell 168: 377-389

3. Moreno JL, Holloway T, Albizu L, Sealfon SC, Gonzalez-Maeso J (2011) Metabotropic glutamate mGlu2 receptor is necessary for the pharmacological and behavioral effects induced by hallucinogenic 5-HT2A receptor agonists. Neurosci Lett 493: 76-79.

4. González-Maeso J, Ang RL, Yuen T, Chan P, Weisstaub NV, et al. (2008) Sealfon SC Identification of a serotonin/glutamate receptor complex implicated in psychosis. Nature 452: 93-97.

5. Huang A, Amos TB, Joshi K, Wang L, Nash A (2018) Understanding healthcare burden and treatment patterns among young adults with schizophrenia. J Med Econ 21: 1026-1035.

6. Benros ME, Mortensen PB, Eaton WW (2012) Autoimmune diseases and infections as risk factors for schizophrenia. Ann N Y Acad Sci 1262: 56-66. [crossref]

7. Schizophrenia Working Group of the Psychiatric Genomics Consortium (2014) Biological insights from 108 schizophrenia-associated genetic loci. Nature 511: 421-427.

8. Zimering MB, Mirkovic N, Pandya M, Zimering JH, Behnke JA, et al. (2016) Toxic Immunoglobulin Light Chain Autoantibodies are Associated with a Cluster of Severe Complications in Older Adult Type 2 Diabetes. J Endocrinol Diab 3: 1-14.

9. Zimering MB (2017) Diabetes Autoantibodies Mediate Neural- and Endothelial Cell- Inhibitory Effects Via 5-Hydroxytryptamine- 2 Receptor Coupled to Phospholipase C/Inositol Triphosphate/Ca2+ Pathway. J Endocrinol Diab 4: 1-10.

10. Zimering MB (2018) Circulating Neurotoxic 5-HT2A Receptor Agonist Autoantibodies in Adult Type 2 Diabetes with Parkinson's Disease. J Endocrinol Diabetes 5: 10 .

11. Weiner DM, Burstein ES, Nash N, Croston GE, Currier EA, et al. (2001) 5-hydroxytryptamine2A receptor inverse agonists as antipsychotics. $J$ Pharmacol Exp Ther 299: 268-276. [crossref]

12. Schmid CL, Raehal KM, Bohn LM (2008) Agonist-directed signaling of the serotonin 2A receptor depends on beta-arrestin-2 interactions in vivo. Proc Natl Acad Sci U S A 105: 1079-1084. [crossref] 
Mark B. Zimering (2019) Schizophrenia Plasma Autoantibodies Promote 'Biased Agonism' at the 5-Hydroxytryptamine 2A Receptor: Neurotoxicity is Positively Modulated by Metabotropic Glutamate 2/3 Receptor Agonism

13. Luttrell LM, Roudabush FL, Choy EW (2001) Activation and targeting of extracellular signal-regulated kinases by beta-arrestin scaffolds. Proc Natl Acad Sci US A 98: 2449-2454.

14. Schmid CL, Bohn LM (2010) Serotonin, but not N-methyltryptamines, activates the serotonin $2 \mathrm{~A}$ receptor via a $\beta$-arrestin $2 / \mathrm{Src} /$ Akt signaling complex in vivo. $J$ Neurosci 30: 13513-13524.

15. Hennessy BT, Smith DL, Ram PT, Lu Y, Mills GB (2005) Exploiting the PI3K/AKT pathway for cancer drug discovery. Nat Rev Drug Discov 4: 988-1004. [crossref]

16. Johnsen JI, Segerström L, Orrego A, Elfman L, Henriksson M, et al. (2008) Inhibitors of mammalian target of rapamycin downregulate MYCN protein expression and inhibit neuroblastoma growth in vitro and in vivo. Oncogene 27: 2910-2922. [crossref]

17. Johnsen JI, Segerström L, Orrego A, Elfman L, Henriksson M, et al. (2008) Inhibitors of mammalian target of rapamycin downregulate $\mathrm{MYCN}$ protein expression and inhibit neuroblastoma growth in vitro and in vivo. Oncogene 27: 2910-2922. [crossref]

18. Fuxe K, Agnati LF, Jacobsen K (2003) Receptor heteromerization in adenosine A2A receptor signaling: relevance for striatal function and Parkinson's disease. Neurology 61: 19-23.

19. Wang J, Wang Z, Liu R (2018) Metabotropic glutamate receptor subtype 2 is a cellular receptor for rabies virus. PLoS Pathogens 14
20. Muguruza C, Meana JJ, Callado LF (2016) Group II Metabotropic Glutamate Receptors as Targets for Novel Antipsychotic Drugs. Front Pharmacol 7: 130.

21. Zimering MB, Behnke JA, Thakker-Varia S, Alder J (2015) Autoantibodies in human diabetic depression inhibit adult neural progenitor cells in vitro and induce depressive-like behavior in rodents. J Endocrinol Diab 2: 11.

22. Aghajanian GK, Marek GJ (2000) Serotonin model of schizophrenia: emerging role of glutamate mechanisms. Brain Res Brain Res Rev 31: 302-312.

23. Ansah TA, Ferguson MC, Nayyar T (2011) The 5-HT2A receptor antagonist M100907 produces antiparkinsonian effects and decreases striatal glutamate Front Systems. Neurosci 2011.

24. Baker RA, Casarosa P, Timmerman H (2004) Constitutively active Gq/11-coupled Receptors Enable Signaling by Co-expressed Gi/o-coupled Receptors. J Biol Chem 279: 5152-5161.

25. Mailian KR, Boiadzhian AS, Sogoian AF, Sim RB, Manukian LA (2005) Concentration and protein composition of circulating immune complexes in the blood of patients with schizophrenia and subjects with positive familial history of disease. Zh. Nevrol. Psikhiatr. Im. S. S. Korsakova 105: 55-60

26. Balakrishnan K, Peluso M, Fu M (2015) The phosphoinositide-3-kinase (PI3K)delta and gamma inhibitor, IPI-145 (Duvelisib), overcomes signals from the PI3K/ AKT/S6 pathway and promotes apoptosis in CLL. Leukemia 29: 1811-1822.

\section{Citation:}

Mark B. Zimering, Shree G. Nadkarni (2019) Schizophrenia Plasma Autoantibodies Promote 'Biased Agonism' at the 5-Hydroxytryptamine 2A Receptor: Neurotoxicity is Positively Modulated by Metabotropic Glutamate 2/3 Receptor Agonism. Endocrinol Diabetes Metab J Volume 3(4): 1-8. 